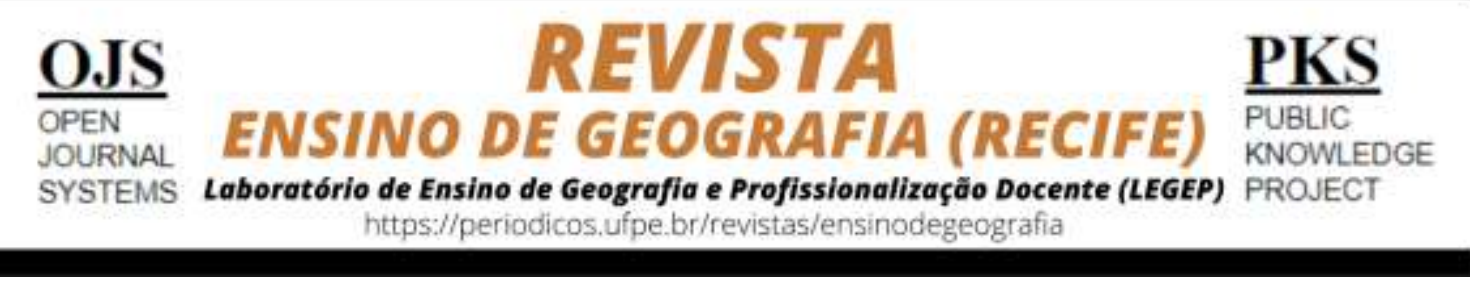

\title{
DESENHO E TOPOFILIA: RECURSOS FACILITADORES NO PROCESSO DE ENSINO-APRENDIZAGEM DA CATEGORIA GEOGRÁFICA LUGAR
}

\begin{abstract}
Rodrigo Nascimento Bentes ${ }^{1}$, Luiz Augusto Soares Mendes²
1 Graduado em ciências naturais com habilitação em Química pela Universidade do Estado do Pará, graduando em licenciatura plena em Geografia pela universidade do Estado do Pará, pós graduado em gestão e docência no ensino superior pela faculdade de educação e tecnologia da Amazônia - FAM, pós graduando em Libras e Metodologia no ensino de Geografia pela instituição Uniasselvi. E-mail: rodrigogeouepa20@gmail.com - ORCID iD: http://orcid.org/0000-0002-1640-0899

${ }^{2}$ Doutor em Geografia pela Universidade Federal Fluminense, mestre, licenciado e bacharel em geografia pela Universidade Federal do Pará. E-mail: lasmgeo@gmail.com - ORCID iD: http://orcid.org/0000$\underline{0002-5145-9415}$
\end{abstract}

Artigo recebido em 17/11/2019 e aceito em 01/04/2020

\begin{abstract}
RESUMO
As expressividades pessoais de cada indivíduo sobre um espaço no qual se manifesta um sentimento, ora negativo, ora positivo, são fundamentais para se identificar a subjetividade e os sentimentos de pertencimento, ou não, a dada porção do espaço. O que deve ter uma relevância sintagmática para se refletir a perspectiva subjetiva das categorias da ciência geográfica utilizadas no dia a dia. Com o objetivo de analisar as práticas metodológicas de professores da educação básica, sobretudo os da disciplina de geografia, vislumbra-se contribuir com novas metodologias para o processo de ensino-aprendizagem dos temas voltados à cartografia e à alfabetização cartográfica; buscando relacionar a confecção de desenhos com representatividades espaciais, a partir das atividades propostas no curso de formação de professores. A metodologia consiste em associar a compreensão sobre o conceito de topofilia, que se expressa quando o espaço faz parte de uma experiência familiar, pessoal e de pertencimento, ou ainda o seu par dialógico, a aversão espacial, que se apresenta na ideia de topofobia. Para tanto, por meio de um relato de experiência, expõem-se alguns exemplos realizados durante uma atividade avaliativa e as formas como foram referenciadas pelos seus expositores através de análise prática do sentimento que se esboça, diante da apresentação em forma de desenho e relacionados às temáticas da espacialidade, da representação e de produtos cartográficos.
\end{abstract}

Palavras-Chave: Topofilia. Topofobia. Alfabetização Cartográfica. Ensino de geografia; categorias geográficas.

\section{DESIGN AND TOPOFILIA: FACILITATING RESOURCES IN THE GEOGRAPHICAL CATEGORY TEACHING LEARNING PROCESS}

\begin{abstract}
The personal expressiveness of each individual about a space in which a feeling is expressed, sometimes negative, sometimes positive, is fundamental to identify subjectivity and feelings of belonging, or not, to a given portion of the space. What must have a syntagmatic relevance to reflect the subjective perspective of the categories of geographic science used in daily life. With the objective of analyzing the methodological practices of basic education teachers, especially those in the discipline of geography, it is envisaged to contribute with new methodologies for the teaching-learning process of themes related to cartography and cartographic literacy; seeking to relate the making of drawings with spatial representativeness, based on the
\end{abstract}


activities proposed in the teacher training course. The methodology consists of associating the understanding of the concept of topophilia, which is expressed when space is part of a family, personal and belonging experience, or even its dialogical pair, spatial aversion, which is presented in the idea of topophobia. For this purpose, through an experience report, some examples made during an evaluative activity and the ways they were referenced by their exhibitors are exposed through a practical analysis of the feeling that is outlined, given the presentation in the form of drawing and related to themes of spatiality, representation and cartographic products.

Keywords: Topophilia. Topophobia. Cartographic Literacy. Geography teaching; geographic categories.

\section{INTRODUÇÃO}

A categoria geográfica lugar assume uma dimensão de reflexão na ciência geográfica a partir da década de 1970, com o advento do "paradigma crítico", como parte forte e representativa, chamada de geografia humanista. Nessa ramificação o lugar aparece como representante da subjetividade, das experiências e das relações sociais que são atribuídas à relação do espaço vivido como parte do desenvolvimento humano e suas relações frente a coletividade e sua vinculação também com o espaço.

É através desse espaço que se constrói a cotidianidade, as formas de análise de como se associa o mundo e sua perspectiva, ultrapassando campos que a própria geografia precisa de outras áreas do conhecimento científico para se fazer como ramo do conhecimento, uma ciência que precisa da interdisciplinaridade. Desse modo, a filosofia existencialista é utilizada na contribuição e na discursão de cunho existencial, vinculada à produção de uma abordagem de perspectiva espacial, propondo assim questionamentos sobre o espaço e as relações dadas com esse, a partir das relações humanas.

A proposta da interpretação sobre as relações sociais e espaciais e as transformações ocasionadas pela ação humana como motivadora, leva em consideração a sua interpretação sobre o que de fato no espaço e no lugar representam formas de categorias geográficas que podem ser definidas com áreas geográficas de ligação e afetividade ao contexto subjetivo quando exposto sobre o espaço vivido.

Nesse sentido, valoriza-se as contribuições dadas pelas interpretações das ciências humanas que com base na filosofia fenomenológica, sobretudo a que diz respeito à reprodução de uma análise estética e da produção artística. Abordagens que utilizam as gravuras, os desenhos e outras formas de representações sociais, que podem ser vinculadas com os sentimentos, as memórias, as vivências e as suas espacializações. Práticas espaciais que estão carregadas de historiografias, dimensões imaginárias e envolvimento nas realidades sociais e culturais. 
A compreensão sobre o espaço geográfico deve ser considerada a partir de uma perspectiva que contribua para além da razão, de maneira a não particularizar os conceitos ou promover análises sincréticas, pois deve ser considerado não somente a representação em cunho científico com um conjunto de significâncias, afetividades, carregadas de efeitos psicológicos e biológicos. Emaranhando-se, nessa perspectiva as sensações e um conjunto de esforços que atribuem significações para a definição e a interpretação desse espaço das subjetividades, das relações e que expressa sentimentos

A busca por uma identificação relacional com o espaço, remonta a uma sensação de empatia e que pode proporcionar lembranças e sensações, atribuídas as vivências historicizadas dos indivíduos, sendo favorável ou não para o sentimento de pertencimento por um lugar, quando assim desenvolvido pelo ser humano através dos seus sentidos, expressas em forma de individualidades, de acordo com as definições de Yi Fu Tuan (2012).

Associado ao uso de representações artísticas, e mais precisamente, nos desenhos que executam registros de determinados lugares, geralmente espaço de empatia, o homem desempenha sobre o enfoque sentimental cognitivo, uma particularidade sentimental por parte de determinado ambiente de forma a trazer para si, um olhar mais afetivo de dados espaços, valorizando-os (OLIVEIRA, 2016).

Para pensarmos em contribuir com uma perspectiva educacional transformadora e ainda trazer para essa construção uma abordagem da subjetividade se coloca como dimensão relevante ao entendimento, refletir que essa postura teórico-metodológica da fenomenologia, não se vincula à realização de uma construção puramente técnica e fechada na razão da ciência. A exposição de relações vitais que a humanidade apresenta com a terra e sua particularidade boas e ruins, manifestam-se no valor que o humano apresentou no dado ambiente que vive, qualificando-o ou não, como importante para a manutenção e condições apropriadas de vida. Assim, é condição importantíssima entender as diversas manifestações e transformações subjetivas no espaço.

A partir destes pressupostos o objetivo deste artigo se assenta em analisar a leitura realizada por parte dos desenhos desenvolvidos por alunos, da disciplina sobre uso de cartografia no contexto da sala de aula; busca-se desenvolver atividades pedagógicas que incentivem aos discente a realizarem representações dos seus espaços de vivências, com uma metodologia que propõe tecer construções afetivas, assim como dos sentimentos acerca dos espaços representados, seja por meio dos desenhos, seja por meio de trajetos ou de croquis. 
Nessas atividades busca-se abrochar as sensações de afeto, a topofilia, ou de aversão e negativas, a topofobia, através de exposição pessoal de suas criações e concepções sobre diferentes exemplos de espaços vividos e atribuição de suas experiências emocionais relacionadas.

Portanto, o artigo se constituiu em quatro sub-topicos, nos quais buscamos tecer um pouco da história do uso dos desenhos como instrumento pedagógico e mostrar sua potencialidade para a alfabetização geográfica. Em outro momento as ideias de topofobia e topofilia e no final a análise dos desenhos como representações espaciais a partir das diversas vivências e sentimentos, como técnica de ensino de geografia.

\section{O USO DO DESENHO: HISTÓRICO, CARACTERÍSTICAS E IMPORTÂNCIA}

Através da leitura e da interpretação do mundo por meio dos espaços geográficos existentes, o uso do desenho como ferramenta e recurso pedagógico, coloca-se como força de expressão daquilo que é sentido, do que é visualizado, do que é cheirado e escutado. Os sentidos são colocados por serem a força da expressão do que é essência e é aparência da vivência humana, eles expõem o que antes era apenas subjetivo, tornandose esboço concreto para melhor representar a expressividade dos seres humanos. (OLIVEIRA, 2016).

O desenho é expressão de uma das formas que melhor evidenciam as representações concretas e abstratas que remontam a uma perspectiva artística desenvolvida pelo ser humano (GOMES, 1996, p. 13). A história do desenho como arte é antiga e pode ser equiparada a história da própria humanidade, em que através de seus costumes e atribuições na forma de valorizar a relação com o espaço habitacional e de sobrevivência, mantiveram a arte e o valor estético como forma de expressão.

Segundo Trinchão (2019) (apud OLIVEIRA, 2016) o desenho se configura como uma forma de divulgação de ações realizadas de acordo com os sentidos que cabe ao ser humano a realizar com busca de se atingir a perfeição, através da leitura de mundo e os elementos do espaço no qual se compõe diversas paisagens. Desde a infância o uso do desenho é uma forma de expressar a liberdade em contato com a natureza, não levando em consideração a arte, mas a justiça por parte do olhar daquilo que se é representado, ou seja, leva a criança a compreender aquilo que está representado mediante a sua expressividade e interpretação pessoal (OLIVEIRA, 2016). 
O uso do desenho parece ter sido infantilizado, vinculado unicamente à fase infantil do desenvolvimento do ser humano. Discordando dessa presunção, vamos de acordo com o pensamento de Yi Fu Tuan (2013, p. 31), quando este geógrafo fenomenólogo, afirma que "No homem adulto são extremamente complexos os sentimentos e ideias relacionados com espaço e lugar". A defesa dessa afirmação vem em decorrência de que é na infância que os imperativos biológicos do crescimento impõem curvas crescentes de aprendizagem e compreensão que são semelhantes e podem, podem transcender a ênfase especifica da cultura.

Assim, o uso do desenho torna-se importante no ensino e na compreensão dos processos nas diversas fases do desenvolvimento biológico e cognitivo do ser humano, o que fora negado, pois essa força de representação da realidade fora tratada como dimensão primária do aprendizado, não sendo dada a devida valorização nas demais etapas da formação institucional ou não formal do ensino. O que comprovou ser totalmente diferente quando usamos a técnica de representação espacial por meio de desenhos como metodologia de aprendizagem nas várias vezes que ministramos a disciplina Cartografia Aplicada ao Ensino.

Para tanto, o uso do desenho como uma ferramenta de ensino é importante e pode ser proposta para todas as áreas e níveis de conhecimento, desde o ensino infantil ao nível superior. O uso de desenhos, se coloca como um meio para se alcançar a aprendizagem, um recurso metodológico para que possamos pensar no que essa técnica pode trazer a partir das diferentes experiências que segundo Oliveira (2016, p.80) tornam-se sintagmáticas na execução dos desenhos.

No contexto escolar, a experiência e o contato com a natureza é realizada na forma de expressividade socioespacial que se dá na inserção das atividades artísticas que vem a valorizar a concepção de arte, de liberdade e pode evidenciar o sentimento desenvolvido através de pinturas livres, que valorizem a subjetividade do autor, manifestada nos desenhos produzidos.

A orientação atribuída à confecção de desenhos e a forma como se estimula por meio de repetição ou como cópia de uma forma determinada, instrumentaliza segundo Oliveira (2016) todos os sentidos humano - do olhar ao tato. Desenvolvendo o ser humano para diversas funções, com brevemente a escrita, relacionado a infância, demostrando a expressividade da criança; e mais tarde a manifestação de sentimentos mais amadurecidos por parte da realização, sobretudo na vida adulta. 
Para ilustrar as afirmações anteriores deve-se depreender que a cartografia desenvolvida na perspectiva geográfica é uma atribuição de uma linguagem que está sob o sentido humano da visão. O desenho desenvolve uma comunicação com quem está interpretando, com que ler e se torna um sistema de simbologias, apanhados para compreender o verdadeiro sentido das ações do espaço e as relações humanas nestas sujeições.

Ao recorremos ao pensamento de Castellar (2011) quando a autora expõe que a educação cartográfica é repleta de estratégias metodológicas de interpretação na qual a cartografia se insere, onde a visualização das diversas informações na produção no espaço contribui para a capacidade de desenhar e de desenvolver croquis, atribuindo sentido ao espaço vivido, interpretando e relacionado quando as atividades pedagógicas são expostas.

Em consideração a aprendizagem cartográfica na geografia, que inclui a alfabetização cartográfica, busca-se entender as experiências que são direcionadas a todos e, que indiferentemente da faixa etária, precisam compreender a importância do uso da cartográfica na forma como se vê e percebe o mundo em volta, assim como o seu cotidiano. Não apenas saber dos pontos cardeais, colaterais ou sub-colaterais, mas como o desenho pode expressar os caminhos, as latitudes e as longitudes, juntamente com a ideia de lateralidade.

Ao ressaltar tal pensamento Francischett (2012) esboça em sua análise sobre o aprendizado da cartografia, que as experiências advindas dessas relações de aprendizagem, consolidam uma forma de interpretar o mundo e por meio da cartografia, representar essa concepção. Já para Oliveira (2016) a cartografia apresenta por finalidade a representação espacial especifica ou geral, quando analisada e pode ser atribuída em diversas formas de representação sendo importante para o campo geográfico como linguagem. A cartografia pode ser ministrada pelo docente em forma de desenhos e também como alternativa de linguagem, nesta perspectiva, também levando em consideração tal ação no contexto de interpretação e de entendimento.

Para tanto, entender os usos e a importância do desenho para o ensino da cartografia, perpassa por enquadra-lo como recurso pedagógico e metodológico facilitador do processo de ensino-aprendizagem de uma espécie de letramento cartográfico. A fim de aprofundar essas discussões e ideias, vamos melhor inserir e situar o lugar como uma categoria geográfica que apresenta o conceito de espaço topofílico que possui tendência à fenomenologia. 


\section{A CATEgoria geográfica LUgAR NA ANÁliSe dOS ESPAÇOS TOPOFÍLICOS}

Com uma perspectiva fenomenológica, queremos situar a categoria geográfica lugar, para além de um conceito que é o cerne desta pesquisa, entender como uma ideia ampla que parte da compreensão das relações sociais, subjetivas e das experienciações culturais, comunitárias e individuais das determinadas sociedades, que exprime interagir o espaço com a relação entre o homem e o mundo, entendidas através da subjetividade e da afetividade de cada um, que particulariza-se através de simbolismo sobre objetos de vivencias do meio, ou seja, em seus cotidianos.

Segundo Mendes et al (2017) a categoria lugar deve ser destacada como uma experiência de afetividades e de simbolismos, e partindo desses espectros se pode chegar a uma valorização do que seja essencial no cotidiano. São possibilidades para quem vivência o lugar, colocando-se como uma construção singular sobre os diferentes contextos pelo que passa o ser humano na construção da sua vida social.

Dessa maneira, determina-se o lugar a partir de uma corrente chamada de Geografia Humanista. Para tanto, Mendes et al (2017, p. 155) aponta que o lugar,

(...) passa a ser visto como algo atrelado ás subjetividades da experiência humana, tornando-se uma categoria de grandes discussões na Geografia a partir de teóricos humanistas tais como Yi-Fu Tuan que aborda o lugar como categoria que nos permite compreender o mundo a partir de vivências reais e conhecidas das realidades no qual estamos inseridos. (MENDES et al, 2017, p. 155).

O lugar neste sentido aparece com a perspectiva de pertencimento, na qual se obtém a estabilidade e a segurança, causando dualidades de sensações de forma particular, que segundo Yi-Fu Tuan (1983) podem variar de conforto ou desconforto, afetividade ou repulsão, de atração ou negação, tendo como na perspectiva humanista, a conceituação do termo topofilia para as sensações agregadas positivamente e topofobia para a as sensações que são desagradáveis.

Os gestos de subjetividade no espaço vivido pelos seres humanos resultam em sentimentos de pertencimento ao lugar que é também definido como topofilia, ou de topofobia que seria o inverso, o sentimento de falta de empatia ao lugar, defendidos por Yi Fu Tuan (1983). O sentimento topofílico é resultante das relações entre a pessoa e o 
ambiente físico unidos a temporalidade de forma a se construir sentimentos que fora alicerçados ao longo da vivencia no espaço.

As relevâncias destas atribuições sensíveis decorrem da percepção e da vivência de lugares particulares, onde se estreitem laços com tal espaço compreendendo a historicidade recorrentes deste lugar, que para os que vivem, apresentam consciência do espaço vivido, simbolizando através de um elo, que consequentemente conscientiza-se do mundo, daquilo que atribuído ao campo das experiências, proporcionando afeto ou não, de tais espaços surgem como consequência.

Assim sendo, segundo Santos (2005, p. 158) a percepção do mundo se dá de forma empírica, na categoria lugar, onde se define entre a interação, a história e os ambientes vividos o que promove a ligação destes, em uma fundamentação nas experiências marcadas pela prática do cotidiano e os vínculos afetivos que cada lugar representa.

\section{TOPOFILIA: APROXIMAÇÕES CONCEITUAIS E SUBJETIVIDADES NAS REPRESENTAÇÕES DESENHISTICAS}

Para tratarmos das dimensões conceituais da ideia de topofilia, precisamos partir da concepção bastante valorizada nas abordagens fenomenológicas, a de que o ser humano apresenta relações com o espaço através de seus cinco sentidos: visão, audição, tato, paladar e olfato. Perspectiva que expressa o caráter particular de ser humano para ser humano, devido apresentar certa dependência de certos sentidos que o conecta com o mundo (TUAN, 2012, p.22).

A busca por um significado que abarque e preze por compreender as diversas formas existentes de vida nos faz analisar e entender que há particularidades entre os seres humanos, sobretudo no que diz respeito a sua percepção norteada pelas relações sociais nos diversos contextos espaciais, nos quais a humanidade vivencia junto o espaço geográfico.

Yi Fu Tuan (2012, p.8) aporta esse pensamento em meio a um período conturbado na sociedade mundial - o período pós-guerra, em que havia uma espécie da destruição da perspectiva afetiva das pessoas. As relações que os homens mantem em sociedade, junto ao meio que vivem, através de seus contextos, tempo e espaço, pode implicar em uma relação de proximidade ou aversão com o próprio lugar, na qual é denominada respectivamente: Topofilia e Topofobia. 
Segundo Yi Fu Tuan (2012, p. 9) devemos produzir uma geografia que se relaciona e seja voltada para o ser humano, englobando a experiência geográfica, buscando a espacialidade e relacionada com a dimensão existencialista, psicológica, cultural, o que não deixa de ser próprio da geografia, por essa ciência visar uma forma de compreensão entre o humano e a natureza. Diante dessas designações o autor entroniza que a topofilia consista no "(...) elo afetivo entre a pessoa e o lugar, ou o ambiente físico". É diferenciado dos outros seres, pois é único sobre a perspectiva humana e leva, diferentemente, dos animais a um processo de empatia e cooperação quanto à realidade do próximo, quando valorizado pelo sentimento alheio dos seres humano próximos ou mais distantes. (TUAN, 2012, p. 19).

Um destaque que deve ser dado entre os sentidos humano para a compreensão da experiência com o espaço é o da visão. Sentido que para o supramencionado autor atribui certas características particulares aos humanos, o que os possibilitam expressar relações por meio do olhar e da interpretação visual, isto dado pela evolução do homem tendo a possibilidade visual mais apurada e de forma colorida, diferente de outros seres com visão monocromática ou até mesmo que não tem a visão como sentido de maior utilidade.

Sobre o tato, a percepção por conta do contato sensorial, traz ao ser humano a possibilidade de ter habilidade de informações sobre o mundo e diferenciar os objetos. Essa habilidade pode ocorrer de maneira muito mais aguçada quando se é limitando de outro sentido, como no caso da visão. Segundo Yi Fu Tuan (2012, p. 24) o tato é uma forma de resistência promovendo a experiência, um sentido de persuasão da maneira como se é direcionada uma realidade diferente de uma imaginação, em outras palavras, através do toque, transformar o irreal no real e palpável.

Já em relação ao sentido da audição o referido autor apresenta que essa possui “desvantagens" sob os outros sentidos, pois no caso da audição, não retém tantas informações como diferente da visão, e ainda precisa se adaptar de acordo com os sons distribuídos no ambiente. Não reconhecendo boa parte das sonoridades por conta do alcance da frequência sonora do humano ser projetado diferente de outros seres vivos.

O autor contribui explicando que a importância da audição para a "apreensão da realidade" quando se é perdido esse sentido, no caso a surdez, a pessoa tem alterações psicológicas, como: isolamento social, depressão, estresse e fácil irritabilidade.

Com relação aos sentidos do olfato, Yi Fu Tuan (2012) inicia por informar que ele é o responsável pela familiaridade ao espaço vivido, pois com ele é condicionado por apresentar diferenças entre os seres, sendo para alguns animais, usado no instinto de 
sobrevivência no caso dos animais carnívoros selvagens. Segundo o supramencionado autor o homem da modernidade negligencia esse sentido, afastando a amplitude desta percepção aos odores limitando-se somente a maus-cheiros, que acabam impedindo a coleta de informações, oferecidas pelo sentido olfativo. (TUAN, 2012, p. 27)

Através do olfato é possível de se remeter às lembranças que foram vivenciadas em outros momentos pelo ser humano. O sentido que revivifica e carrega a emoção de acontecimentos passadas e que foram de certa forma marcante, ora positivamente, ora negativamente; que de acordo com o vivido pelo indivíduo em dada situação apresentada, venha a ser lembrado de alguma forma e instigados.

O autor não cita atribuição dada ao sentido paladar, porém junto a esta perspectiva sensorial para a compreensão deste mundo diverso de informações, que interagem em todos estes sentidos supracitados, constituindo uma interpretação pessoal de acordo com a cultura e sua necessidade de constituir um sentido o dado objeto, ou localidade, ou odor que devem ser usados de forma coletiva desenvolvendo a percepção com forma de ação que busca entender o mundo (TUAN, 2012, p.28-29).

Porém a partir das experiências trabalhadas em sala de aula, já conseguimos fazer com que os discentes conseguissem descrever lugares e até mesmo paisagens diferentes a partir das suas lembranças do gosto da comida regional amazônica, com destaque para a paraense. O paladar dessa maneira faz com que consigamos guardar e especializar nossas práticas sociais, o que nos impressionou e apareceu como elemento novo na análise das experiências sociais, que marcam os espaços e podem ser utilizadas como recurso metodológico no ensino da geografia.

O termo topofilia, portanto, é empregado como neologismo e traz como referência a afetividade dos seres humanos com dado espaço, ambiente, diferenciando-as por características particulares entendidas pela subjetividade. A forma de intermediar tal sentimento de relação topofílica com dado lugar varia de como se atribui o sentimento do indivíduo, que está vinculado a um dos cinco sentidos e, ainda, pode ser puramente estético, belo, fugaz, de forma tátil, porém com certa dificuldade de expressividade quando se atribui o sentimento de moradia, de lar, e as formas de como se constitui a referência espacial e a sua forma de vida. (TUAN, 2012, p.135-136). 


\section{RECURSOS E ORIENTAÇÕES PARA A CONSTRUÇÃO DE REPRESENTAÇÕES ESPACIAIS A PARTIR DE DESENHOS}

Com base nos pensamentos de Castellar (2011) e de Oliveira (2016) para quem há uma importância sintagmática do desenho no ensino de Geografia, sobretudo, quando este é articulado com a cartografia escolar. Propôs-se ao ministrarmos a disciplina Cartografia Aplicada ao Ensino no Curso de Licenciatura plena em Geografia da Universidade do Estado do Pará, no primeiro semestre do ano de 2019, semestre que chamamos de $2019.1^{1}$.

Partimos da perspectiva e da concepção de que a linguagem do desenho associada à cartografia tem uma enorme potencialidade para dinamizar o ensino de geografia na escola. Assim, pensamos no momento de preparo do plano de curso da disciplina em várias possibilidades de como a cartografia pode ser didatizada em um curso de formação de professores, para que esses discentes, professores em formação possam utiliza-la no contexto escolar.

Propusemos uma atividade durante as discussões do texto de Oliveira (2016) onde em um dos pontos fora tratado que além dos saberes da matemática e da geometria, devese ter em mente, como professor e como cidadão, que o desenho também conduz ao entendimento dos aspectos e fenômenos da ciência geográfica. E partindo dessa concepção, propusemos que na sala de aula, a confecção de desenhos, que deviriam ser utilizados para representar os lugares, uma vez que é através do desenho que a criança começa a registrar os elementos contidos no espaço e a se perceber como sujeito construtor e transformador da paisagem, do espaço e mesmo dos lugares.

A partir da concepção de que as primeiras apreensões da realidade decorrem da interação social, propôs-se uma atividade em que se solicitou que cada aluno fizesse uma representação de um espaço que o mesmo tivesse familiaridade e logo depois da confecção do desenho livre, com a utilização de uma folha de papel A4, e a disponibilidade de vários lápis multicoloridos. A ideia de constituiu e utilizar o desenho

\footnotetext{
${ }^{1}$ O Curso de Licenciatura Plena em Geografia da Universidade do Estado do Pará (UEPA) é ofertado nos regimes modular e regular. Na cidade de Belém e de Castanhal (Região Metropolitana de Belém) o curso funciona com a oferta de disciplina de maneira regular semestralmente. Nos campi do interior o curso que é ofertado nas cidades de Conceição do Araguaia, Barcarena e Igarapé Açu, funciona por módulos de disciplinas dentro do semestre. Cada disciplina ocorre em dias dentro da carga horária prevista no Projeto Político Pedagógico do curso, aprovado pela Conselho Universitário (CONSUN/UEPA) e pelo Conselho de Educação do Estado do Pará.
} 
como uma disposição natural e como concepção pedagógica, que atende para além do ensino das artes e da escrita (CARTELLAR, 2016).

Então, colocou-se o desenho dos trajetos como forma de representação do espaço geográfico. E após o termino do desenho era necessário compartilhar entre os colegas de classe. Os desenhos eram deixados em uma mesa no centro da sala de aula e de maneira aleatória um discente pegava o desenho de outro colega de sala, esse fazia a análise do desenho, e o que conseguia entender e identificar compartilhava com os demais alunos presentes em sala. O efeito desse processo coloca-se como uma espécie de suposição de ideias expressas através do desenho, cada um iria ser interpretados por seus significantes e significados, os signos do desenho alheio e do próprio confeccionado.

Após essa apresentação de forma aleatória conforme escolhiam o desenho, citavam o nome da pessoa que mais o desenho era compatível e fazia-se uma interpretação do que o mesmo se retratava, após um breve momento de explanação era direcionado, ao aluno que o confeccionou, tendo o direito de pronunciar sobre o mesmo e o que subjetivamente, o desenho representava.

Obteve-se como resultado da atividade e da disciplina, que o desenho pode representar os lugares da subjetividade humana, sendo construídos de maneira lúdica mexem com o emocional dos seus autores quando exposto por eles mesmo, em uma espécie de explicação do significado de cada elemento presente e desenhado. Concepções registradas com a forma de comportamento e de expressão de alguns desenhos expostos pelos seus desenhistas, os quais apresentamos a seguir, conforme a disponibilidade e autorização dos seus autores.

Busca-se mostrar nessas representações forma da percepção dos alunos produzidas por meio do desenho, assim como as ligações e experiências espaciais, entendendo-as como espaços de topofilia. Para tanto, no primeiro desenho escolhido ilustrar esse artigo, exposto na figura 01, é possível visualizar o aspecto religioso como importante a memória espacial da sua autora, assim observem: 


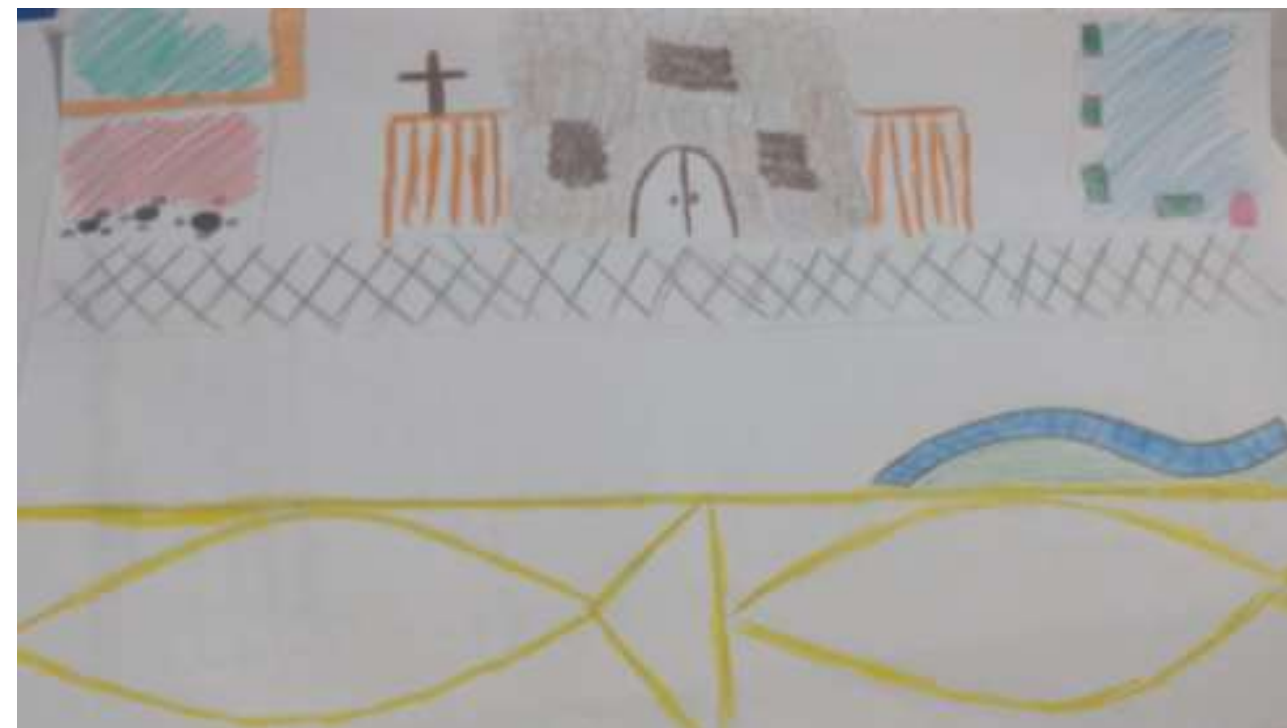

Figura 01: Desenho da discente B.A.- Descreve a Igreja de Pedra e o piso da Orla Ribeirinha da Cidade de Vigia de Nazaré-Pará.

Observa-se no desenho, e nos relatos da discente, que a representação da "Igreja de Pedra", um dos ícones da colonização do espaço amazônico e fora tornada patrimônio material histórico da cidade de Vigia de Nazaré, no nordeste do Estado do Pará. A construção está de frente para a orla da cidade, que é banhada pelo Rio Guajará Mirim. O rio representa um elemento importante, sobretudo na simbologia da cultura, da vida em odos os aspectos sociais, com destaque para as relações econômicas da região e das cidades adjetivada de ribeirinhas. A autora deste desenho (figura 01) relata que frequentemente ia na frente desta igreja para encontrar com os amigos, expressar seus preceitos religiosos, e também para refletir sobre acontecimentos de sua vida pessoal.

Temos, então, o desenho utilizado para revelar os sentimentos, demostrando a fé e os vínculos culturais das cidades na Amazônia. Observa-se a representação da hierofânia, os lugares da fé, que são marcados pelos sentimentos de credulidade e de fé. O que nos remete a ligação do espaço as representações sociais do imaginário, seja ele cristão ou da umbanda, seja de qualquer outra religião e manifestação de cresça.

O espaço neste caso tem para a pessoa que a representou uma relação de experiência geográfica, onde psicologicamente a entroniza em uma compreensão de si e do mundo peculiar que a remete as boas lembranças como refletido por Tuan (2012, p. 9). Em vista desta exposição, o espaço topofilico se torna evidente, sendo expressado em uma reprodução singular e cheias de motivações individuais quando desenvolvidas e incentivada de maneira livre pelas pessoas. 
Um segundo desenho analisado, está situado na figura 02, e nos remete a uma representação espacial de uma área verde, como se fosse uma praça, em que se têm a presença de pessoas, como em um ambiente de lazer, mostrado a seguir:

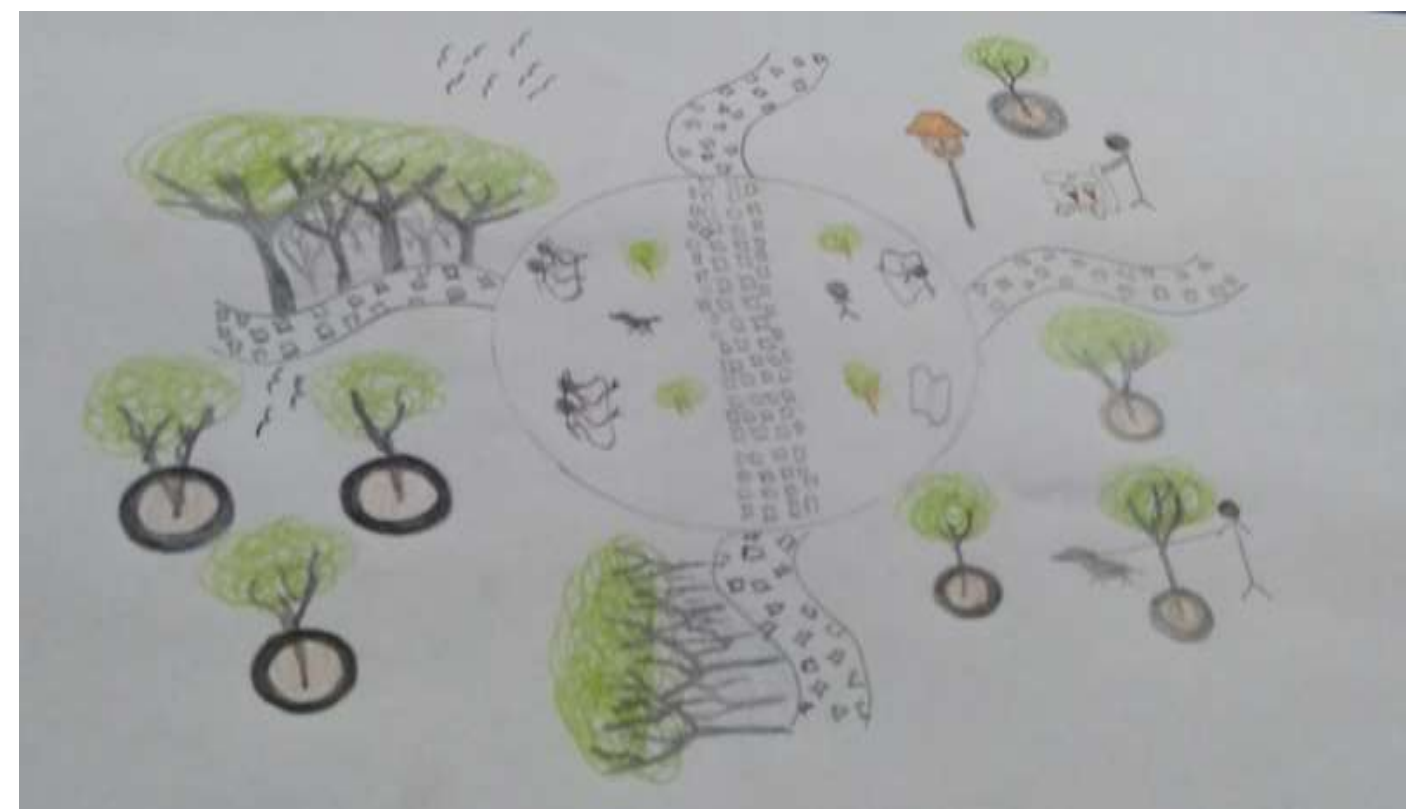

Figura 2: Desenho de J. M. - Representação do lugar da topofilia escolhido pelo aluno

Nessa representação, destaca-se a presença de um ambiente arborizado e que resgata a vivência com os homens e mulheres, expressos em atividades diárias, ora passeando com o cão, ou vendendo cachorro quente, conversando no banco de uma praça entre amigos, ou caminhando por meio do espaço. Segundo a criadora desse desenho, está praça foi criada por ela de sua imaginação, e que para a mesma representa uma relação de familiaridade, já que gosta de ficar só durante seus passeios em ambiente semelhantes, mostrando um pouco de sua relação pessoal com outras pessoas, a mesma em um momento "eu não gosto de estar muito perto das pessoas".

O espaço capturado pela imaginação da discente, também está associada as sensações olfativas relatadas pela mesma, onde com cheiro de terra molhada, cheiro das flores que trazem consigo sentimentos positivos em relação ao espaço que mesmo sendo criado, também inspira um espaço de topofilia como expostos nas dimensões fenomenológicas de Yi Fu Tuan (2012).

Na representação seguinte, figura 03, foi esboçado sentimento por um espaço de entretenimento que traz momentos importantes para a referenciada. 


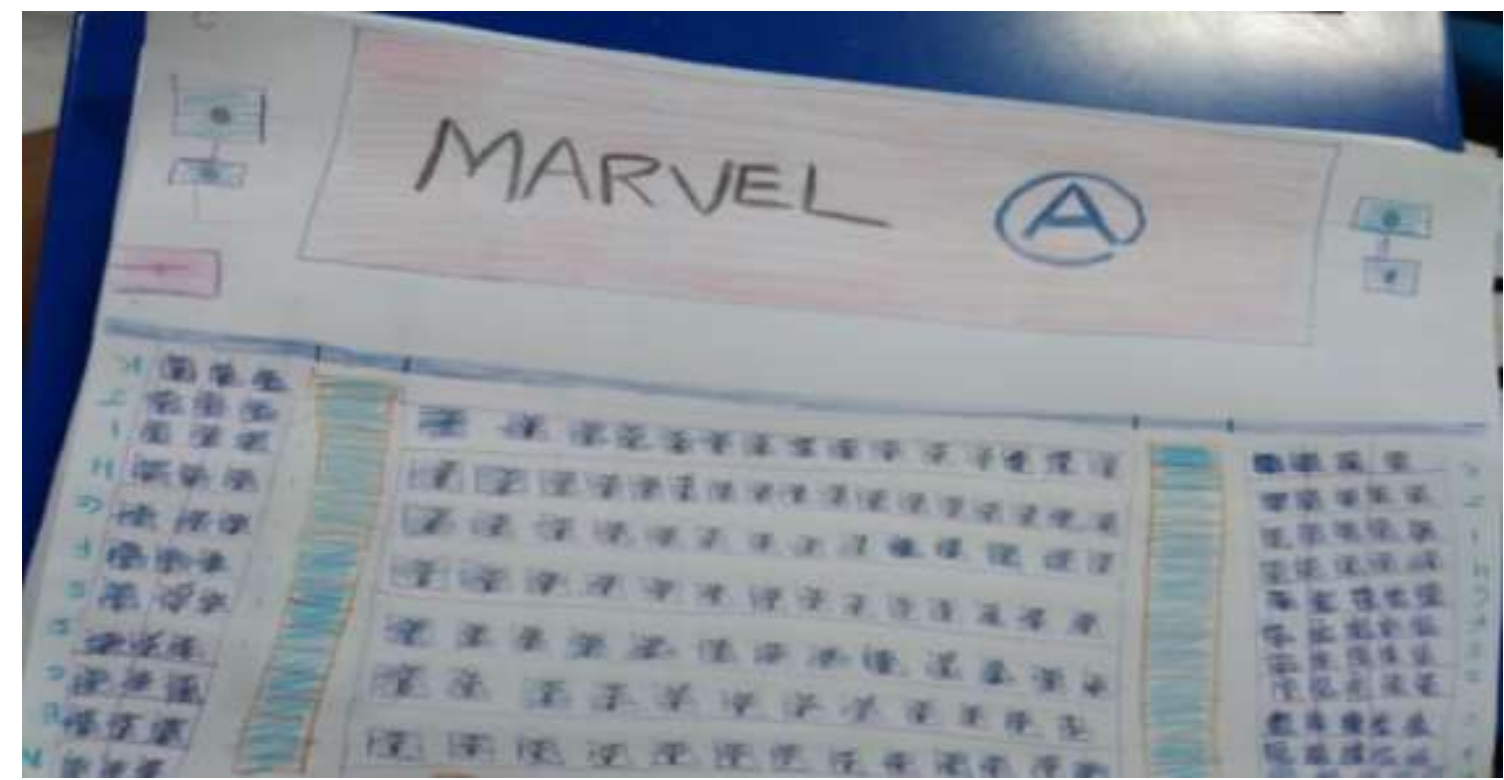

Figura 03: Desenho de M. O. - Representação de uma sala de cinema.

O desenho esboçado pela discente representa um espaço de lazer onde a mesma sempre experimenta sensações diversas quando se encontra neste ambiente de entretenimento, um cinema, sendo exibido um filme, neste caso exposto, de super-heróis chamados de "Advengers", em uma tradução - "Os vingadores". Nesse caso, experiências do sentimento topofílico pelas e nas salas de cinema, que vincula os princípios do cotidiano com "os tempos pós-modernos", onde a sétima arte ocorre sobretudo dentro dos shopping centers.

Dessa maneira, a figura 03, nos situa que em uma sociedade em que as pessoas vivem em ambientes altamente urbanizados. Colocadas para serem consumidoras, como nos dizeres de Lefebvre (1990), uma sociedade burocrática do consumo dirigido, em que grande parte dos seres humanos trocou sua condição de cidadão por consumidores; os shoppings centers, as salas de cinema com toda a reprodução da indústria cinematográfica, que são lugares de consumo se tornam lugares de experiência, que marcam vidas, histórias e memórias, mesmo sendo marcadas pelo dinheiro e apenas pelas relações de troca.

A autora do desenho explicou que a sua relação junto ao ambiente representado, e de como este espaço a levou a sensações, quase "inexplicáveis", contribuindo em manter um sentimento positivo ao espaço vivenciado. O uso da visão junto com a audição é atribuído como os sentidos mais utilizados, onde no espaço relacionado, interagindo entre si, promove maiores condições de sensações e sentimentos, no que se refere à topofilia que traz lembranças, e uma interpretação mais concreta e perceptiva. 
Outro desenho escolhido para compreender a dimensão topofílica do espaço, assim como melhor compreender o desenho como recurso metodológico ao aprendizado da geografia. Na figura 04 observa-se mais uma experiência espacial, essa vinculada ao trabalho.

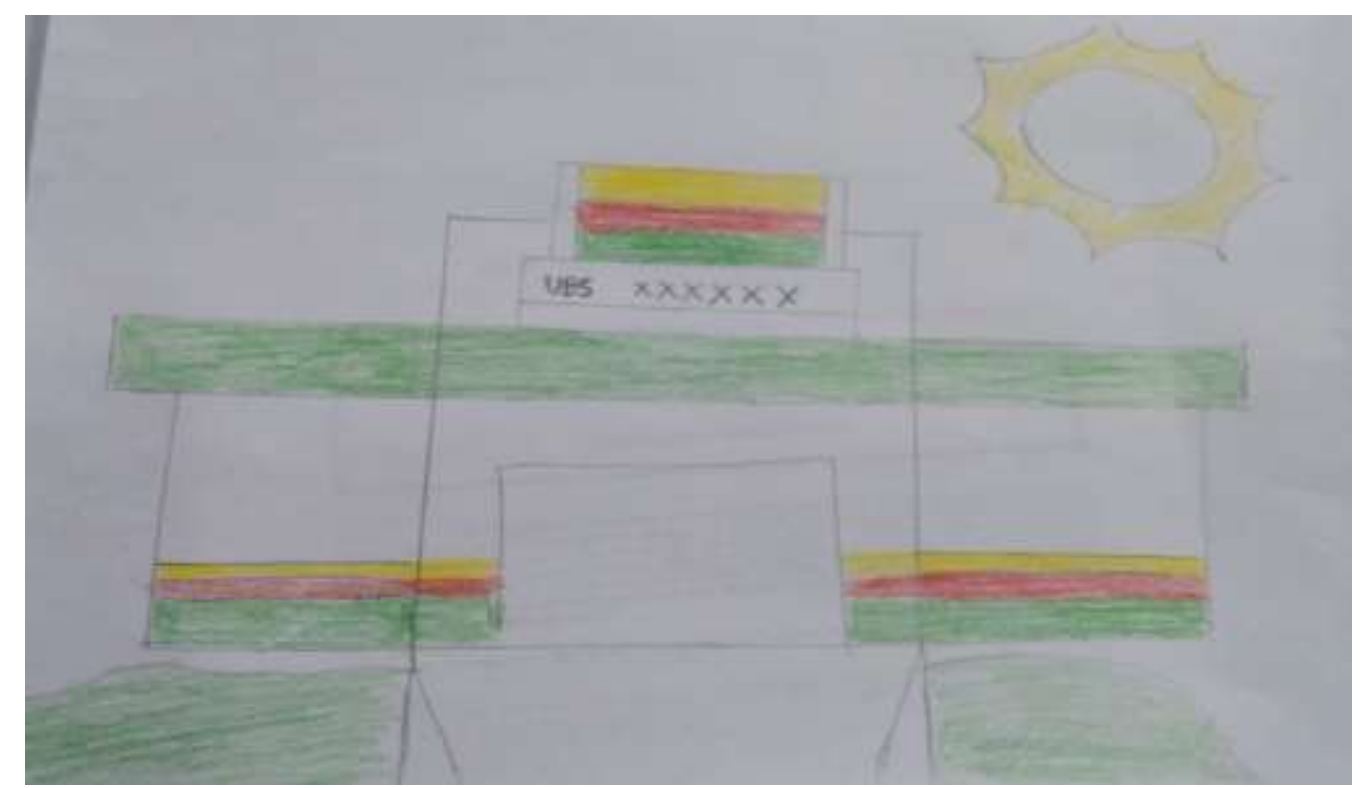

Figura 04: Desenho de R.B. - Representação do espaço escolhido durante a atividade pelo aluno

Essa imagem é de autoria nossa, e nela expressa sentimento de identidade com o espaço, a partir da demonstração do sentimento de afetividade com o local de trabalho. A imagem representa uma Unidade Básica de Saúde (UBS) do Município de Barcarena, que apresentam as cores que são do padrão da administração municipal nas cores verde, amarelo e vermelho.

Este ambiente representado pelo desenho do autor é o local onde realiza suas atividades profissionais, junto de um grupo de trabalhadores na área de saúde, dentre eles Médicos, enfermeiros entre outros, em um ambiente de promoção a saúde e atenção básica, próximo ao seu local de moradia.

$\mathrm{Na}$ exposição sobre o espaço de topofilia representado pela imagem deste prédio de atendimento à saúde, existem dois pontos de análise, pois da mesma forma como pode causar proximidade para algumas pessoas por se tratar de um espaço que se promova o tratamento, prevenção e saúde, podem representar também como um espaço de aversão para outros, não sendo uma definição generalizável, contudo, trazendo atributos relacionados muitos mais que os sentidos, mais ao cognitivo e psicológico e emocional da forma como se deseja manifestar opinião, quanto espaço “topofílico" ou “topofóbico", quando causa distanciamento ou até mesmo sentimento tristes relacionados ao mesmo 
espaço supracitado. Neste sentido, um local de saúde, pode não ser agradável para todos, por ser um ambiente insalubre que as pessoas se direcionam para solucionar problemática em suas saúdes, não sendo espaço de topofilia, mas sim o inverso, de topofobia.

Observa-se que a variedade de interpretações que um recurso artístico, como o uso do desenho pode expressar, contribui na expressividade e na transmissão de sentimentos nas quais podem contribuir, como no caso desta pesquisa, na facilitação da aprendizagem com o uso de recursos facilitadores para compreender melhor as categorias geográficas, neste caso, a categoria lugar.

\section{PARA NÃO CONCLUIR}

Ao relacionarmos as práticas de desenhos livres com o conceito espacial de lugar, sobretudo embasados na concepção fenomenológica de topofilia, buscou-se alcançar outros resultados no ensino de geografia, sobretudo no letramento cartográfico e assim como na alfabetização geográfica. Nossas ações todas foram voltadas para criamos uma espécie de corpus metodológico que fundamentem outros processos de ensinoaprendizagem da geografia como disciplina acadêmica, de um curso de formação de professores, e mesmo a geografia como disciplina escolar.

Então, por meio desse relato de experiência, instiga-se a transmitir os aspectos e sentimentos de positividade quanto às relações artísticas, inseridas no contexto que o indivíduo relaciona e valoriza, contribuindo de forma psicossocial em uma relação interpessoal com outros no meio educacional e também aborda a concepção de que o espaço pode traduzir-se como conceito. Pensando na categoria lugar para além de uma perspectiva apenas cientifica, que desumaniza conceitos, que com o uso dos sentidos podem ligar o homem ao espaço e possibilitar as relações mais efetivas entre si como propõe a perspectiva geográfica, quanto área de análise.

A metodologia utilizada por nós, coloca-se como recursos didático ao complexo processo de ensino-aprendizagem, contribuindo assim para inserir o aspecto do cotidiano, o que é banalizado nas dimensões sociais como efetividade no ensino. A simples disposição espontânea de desenhar suas experiências, suas vivencias e práticas espaciais, e após terminar esses desenhos poder falar sobre ele, utilizando-se de simples palavras e sentimentos. Logo essas exposições de palavras e exposição de sentimentos sobre dados lugares, que para os alunos são considerados de vital importância, ou os atribui sentimento 
de valor, colocam-se como aspectos pouco utilizados no processo de formação dos conceitos, das teorias e no próprio processo de ensino-aprendizagem.

O desenho que outrora descrevia relações, culturas e manifestações humanas, ainda esboça tais sentimentos, porém com um pouco mais de recursos, que garantem maior representação para a compreensão por parte de todos quando apresentados aos sentimentos de outras pessoas, desmistificando e entendendo como favorável a conexão entre o que se propõe pedagogicamente e o processo de ensino-aprendizagem garantido por partes dos aprendizes, em dada dinâmica acadêmica, como neste exemplo de experiência.

As relações propostas por $\mathrm{Yi} F$ Fu Tuan (2012), que são relacionadas multidisciplinarmente, no contexto aplicado através do uso da percepção e uso dos sentidos por partes dos alunos na pesquisa, são levadas em consideração uma vez que conecta o lugar descrito por todos os participantes, a sentimentos advindo de história, relações pessoais, e busca de entendimento sobre o espaço vivido e suas contribuições, que neste caso esboçado por desenhos, representam para a vida de quem constrói no espaço geográfico, uma parte significantes de contribuição para a geografia, disciplinarmente referida.

Portanto, as ideias de utilizar croquis, desenhos livres e desenhos de trajetos nos potencializa a identificar outras práticas de representação, para representar as categorias da geografia, e seu uso na cartografia, ou no ensino de cartografia que se coloca, como uma verdadeira alfabetização. Os discentes relatam tais experiências no final da disciplina, e o que ficou em maior evidência, foi a ideia de como não apenas os mapas produzidos por todo o aparato tecnológico dos programas e dos SIG's podem ser considerados como produtos cartográficos.

Assim sendo, outras formas de pensar a representação espacial surgiram, não descredenciando o mapa, mas ampliando o leque de possiblidade de ensina e alfabetizar geocartográficamente. Uma potencialidade que pode auxiliar na construção de cartografias sociais urbanas, um recurso já utilizado por movimento sociais e grupos de intelectuais, sobretudo como artificio de luta política na região Amazônica. Aspecto que queremos e buscamos sempre conduzir os professores em formação, a entender que a cartografia é um instrumento político, educacional, humanizador, para além do tecnológico e de serventia de empresas e do controle do Estado ou de organização militares e corporativas. 


\section{REFERÊNCIAS}

CASTELLAR, Sonia Vanzella. "A Cartografia e a construção do conhecimento em contexto escolar". In: ALMEIDA, Rosângela Doin de (Org.). Novos rumos da cartografia escolar: currículo, linguagem e tecnologia. São Paulo: Contexto, 2011, p. 121 135.

FRANCISCHETT, Mafalda Nesi. "Aspectos da aprendizagem das representações cartográficas no ensino de Geografia". In: PORTUGAL, Jussara Fraga; CHAIGAR, Vânia Alves Martins (Org.). Cartografia, cinema, literatura e outras linguagens no ensino de Geografia. Curitiba, PR: CRV, 2012, p. 175-184.

GOMES, Luiz Vidal Negreiros. Desenhismo. Santa Maria: Universidade Federal de Santa Maria, 1996.

OLIVEIRA, Simone Santos de. Desenho e cartografia escolar no ensino de Geografia. Geografia, Ensino \& Pesquisa, Vol. 20 (2016), n.3, p. 78-86. 2016

FROEBEL, Friedrich W. A. A educação do homem. Tradução de Maria Helena Câmara Bastos. Passo Fundo: UPF, 2001.

LEFEBVRE, H. A vida cotidiana no mundo moderno. São Paulo: ática, 1990.

MENDES, Raquel Almeida; SOUSA, Elaine da Silva; PEREIRA, Aires José. A importância da categoria lugar no ensino de geografia: um estudo de caso na escola estadual modelo em Araguaína - TO. Revista Tocantinense de Geografia, Araguaína (TO), Ano 06, n. 11, set/dez. 2017.

TRINCHÃO, Glaucia Maria Costa. Didáticas e discursos em defesa do Desenho como objeto de ensino e de sua inserção na instrução pública luso-brasileira. Revista História da Educação. V. 13, n. 29, p. 79-113, set./dez, 2009.

TUAN, Yi-Fu. Espaço e Lugar: a perspectiva da experiência: Difel, 1983.

TUAN, Yi Fu. Topofilia, um estudo da percepção, atitude e valores do meio ambiente; tradução: Lívia de oliveira. Londrina: Eduel, 2012. 